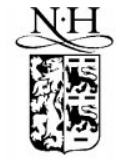

ELSEVIER
International Journal of Industrial Organization 19 (2001) 975-997 $\overline{\text { International Journal of }}$

Industrial

Organization

www.elsevier.com/locate/econbase

\title{
Water resource and power generation
}

\author{
C. Crampes ${ }^{\mathrm{a}, *}$, M. Moreaux ${ }^{\mathrm{b}}$ \\ ${ }^{\mathrm{a}}$ GREMAQ and IDEI, Université de Toulouse I, Toulouse, France \\ ${ }^{\mathrm{b}}$ LEERNA, IDEI and IUF, Université de Toulouse I, Toulouse, France
}

Received 1 November 1998; received in revised form 1 April 1999; accepted 1 September 1999

\begin{abstract}
We propose a simple model of competition between a thermal station and a hydrostation for the production of energy. We show that, despite the static characteristics of the thermal cost function, the thermal output is determined by intertemporal considerations. This results from the scarcity of the water resource which is storable at zero operating cost. We analyze the combination of these technologies in the case of a social planner who maximizes the net total utility from electricity, in the case of private monopoly either regulated or not and, finally, in the case of duopolistic competition in quantities where each private firm operates either a hydraulic power station, or a thermal power station. (c) 2001 Elsevier Science B.V. All rights reserved.
\end{abstract}

Keywords: Water resource; Hydroelectricity; Cournot competition; Closed and open-loop games

JEL classification: L12; L13; Q25; Q42

\section{Introduction}

The liberalization of the electricity industry started at the beginning of the nineties in some pioneer countries such as Argentina and England, and has been adopted more recently in an increasing number of countries, for example in New Zealand (October 1996) and Spain (January 1998). This movement towards more competition is currently accelerating in Europe, since at the end of 1996 the

\footnotetext{
* Corresponding author.

E-mail address: crampes@cict.fr (C. Crampes).
} 
European Parliament promulgated a directive ${ }^{1}$ on common rules for the internal market in electricity stating that “... electricity undertakings are operated... with a view to achieving a competitive market..." (chapter II, article 3). The deadline for the transposition of this directive into the national law systems was February 19, 1999.

Because transmission and distribution of electricity have common features of natural monopolies, most economists consider that active competition can work only for generation. How competition can be effective in generation has recently been an active research field. For instance, based on a theoretical model by Klemperer and Meyer (1989), Green and Newbery (1992) study supply-function competition in the duopoly-like English market. The models (of either Cournot ${ }^{2}$ or Klemperer-Meyer type) are static, where the generation technology is summarized by a short-run cost function. Even if not explicitly specified, the static framework and the hypothesis of an increasing marginal cost suggest that the generation technology these authors have in mind is thermal. ${ }^{3}$

In several countries concerned with the liberalization process, a significant percentage of generation capacity is based on hydrotechnology. The basic problem of most hydroelectric plants is to allocate a scarce resource among several uses at different dates, which means that their problem is intrinsically dynamic. But the management of hydro reservoirs used to be based on dynamic programming techniques that do not include market or strategic considerations. The result is that the economic analysis of the interrelation between heterogeneous technologies devoted to power generation remains to be developed.

The objective of this paper is to build a model that includes thermal technology and hydro technology in order to emphasize how the presence of a hydroelectric station drastically changes the optimal as well as the market equilibrium outputs of the thermal station: despite an a priori static technology, the thermal plant facing an hydroplant has to be managed as if it were dynamically connected. The conclusion is that most standard models used so far to analyse competition in generation need to be improved by the addition of intertemporal features in order to give an accurate representation of the market mechanisms in countries where hydrogeneration is important.

At this stage, it is worthwhile insisting on the peculiar characteristics of the

\footnotetext{
${ }^{1}$ Directive 96/92/EC, available on line at http://www.europa.eu.int

${ }^{2}$ For instance see Borenstein and Bushnell (1997).

${ }^{3}$ The other main references on the economic analysis of competition in power generation are Von der Fehr and Harbord (1993), Wolak and Patrick (1997) and Wolfram (1998). They all are static models. For exceptions, see Scott and Read (1996) who refer to a Cournot equilibrium concept to optimize the management of reservoirs and Ocaña and Romero (1998) who incorporate hydrogeneration capacity in an oligopolistic market to analyse the potential performance of the Spanish spot electricity market.

${ }^{4}$ In New Zealand $80 \%$ of production is from hydro, in Brazil, $97 \%$ and in Norway, $98 \%$.
} 
water resource. First, it can be stored in dams and second, it has an exogenous annual profile, intrinsically random but with a rather good predictability.

Regarding the first quality, in this paper we deal exclusively with water kept in dams, that is a scarce resource for which any unit used today means one unit less available tomorrow. This is obviously not the case when the power station uses the water flow of a river that cannot be stored. Some other energy flows are storable: for instance solar energy can be stored in biomass. But it is not competitive at all with hydrostations or with hydrocarbons.

Regarding now the second quality, water is very different from hydrocarbons for electricity generation for two reasons. The first reason is that the hydrocarbon stocks are so huge that it would be irrelevant to consider the possibility to exhaust them in the short term. On the contrary, the water stored in a dam can be provisionally exhausted since it is renewable according to a forecast cycle. The second reason is that there exist markets for hydrocarbons so that their spot and forward prices are exogenous at the level of individual thermal power stations, while for each individual hydroplant the price of the resource is endogenous.

Obviously, any plant used for power generation, thermal or otherwise, is to be managed taking account of its depreciation, which means that its management should always be dynamic. But since this is not specific to one technology and also because most firms use accounting rules that allow them to limit the management horizon to one single period, we will disregard the capital depreciation dimension. Rather, we focus on the competition between an intrinsically static technology, named thermal technology, and an intrinsically dynamic one, named hydroelectric technology.

In this paper, we explore the first-best dispatching and the monopoly and duopoly equilibria in an economy where the two technologies compete. We consider only short run decisions, which means that both the thermal capacity and the hydro equipment are given.

The paper is organized as follows. In Section 2, we set up the model. Then, in Section 3 we determine the outputs of thermal and hydro energy that maximise welfare. In the same section, we study the circumstances under which it is optimal to stop generation in one of the stations for some time interval. Section 4 is devoted to the analysis of the operation of both plants by a private monopoly, either regulated or not. In Section 5, we analyze a model of competition in quantities between the two types of producers. In Section 6, we show that if the producers cannot commit at the outset to quantities to supply at both periods, the relevant competitive setting is no longer the standard Cournot competition, but a more dynamic one. We show that in this no-commitment case, the Markov subgame-perfect equilibrium is significantly different from the static Cournot outcome. We briefly conclude in Section 7.

\footnotetext{
${ }^{5}$ We do not know any country in which water itself is charged to the hydropower producers.
} 


\section{Thermal and hydraulic generation}

We consider a discrete intertemporal model where electric power can be generated by means of two plants, one using a hydraulic technology and the other one using a thermal technology. Operations are planned for two periods labelled $t=1,2$.

Let $u_{t}\left(q_{t}\right)$ be the total utility from consuming the quantity of electricity $q_{t}$ during period $t$. This function is assumed strictly concave with a maximum at $\hat{q}_{t}$.

Electricity is a perfectly standardized commodity so that the outputs from any plant are perfect substitutes for the purpose of consumption. This hypothesis of substitutability is reasonable as long as consumption is measured only in terms of quantity of energy, without any reference to another dimension, for instance to quality measured by the reaction lag of the generators. The demand for energy is highly variable during a year. The main part of this variability is easy to forecast and one can for instance distinguish peak demand (winter working day) and off-peak demand (holiday). The remaining variable part results mainly from changes in the weather. Therefore, the level of demand randomness is highly dependent on the accuracy of weather forecasts. In this paper, we assume that demand in each period is perfectly known.

The technical characteristics of the thermal plant are the following. Let $q_{t}^{\mathrm{T}}$ stand for the thermal output during period $t$ and $c_{t}\left(q_{t}^{\mathrm{T}}\right)$ for the cost of producing $q_{t}^{\mathrm{T}}$. We assume that $c_{t}$ is increasing and convex:

$$
c_{t}^{\prime}\left(q_{t}^{\mathrm{T}}\right)>0, \quad c_{t}^{\prime \prime}\left(q_{t}^{\mathrm{T}}\right) \geqslant 0 \quad \forall q_{t}^{\mathrm{T}} \in\left(0, \bar{q}^{\mathrm{T}}\right)
$$

where $\bar{q}^{\mathrm{T}}$ is the installed capacity. These hypotheses include the standard framework of a total cost which is linear up to the limit of the generation capacity

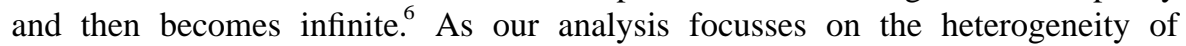
generation means, we assume that transmission costs are zero in any case: there is neither transport loss nor any congestion of the lines. Finally, we assume first that the thermal plant has a positive net social utility in the absence of water resource, that is $u_{t}^{\prime}(0)>c_{t}^{\prime}(0), t=1,2$, and second that the installed capacity is large enough so that the thermal capacity constraint is never binding.

Now, let us consider the hydro-plant. Let us denote by $S$ the exogenous stock of water that can be used between the beginning of period 1 and the end of period 2 . This stock is perfectly known and measured in electricity generation units so that we can directly write the water resource constraint as: ${ }^{7}$

\footnotetext{
${ }^{6}$ See for instance Williamson (1966).

${ }^{7}$ An alternative modelling of this constraint is presented in the Appendix of Crampes and Moreaux (1999).
} 


$$
q_{1}^{\mathrm{H}}+q_{2}^{\mathrm{H}} \leqslant S .
$$

where $q_{t}^{\mathrm{H}}$ stands for the hydroelectric output during period $t$.

In order to keep the model as simple as possible, we assume that the generation of electricity in the hydroplant incurs no variable cost. The cost, if any, does not change with the taking of water. We also assume that there is no technical limit in terms of water turbine capacity: during each period $t$, the turbines are sufficient to generate at least $\hat{q}_{t}$. Finally, discounting between periods 1 and 2 is neglected.

\section{The first best allocation}

We first characterize the optimal use of the two generation processes. Then, we discuss various possible corner solutions.

\subsection{Optimal use of the generation processes}

The first best outcome is the combination of outputs $\left\{q_{t}^{\mathrm{i} *}, \mathrm{i}=\mathrm{H}, \mathrm{T}, t=1,2\right\}$ that maximizes the net social surplus:

$$
\begin{aligned}
& \text { (P.1) } \max _{\left\{q_{t}^{\mathrm{i}}\right\}} \sum_{t=1,2}\left[u_{t}\left(q_{t}^{\mathrm{T}}+q_{t}^{\mathrm{H}}\right)-c_{t}\left(q_{t}^{\mathrm{T}}\right)\right] \\
& \text { s.t. } \quad S-q_{1}^{\mathrm{H}}-q_{2}^{\mathrm{H}} \geqslant 0 \text { and } q_{t}^{\mathrm{i}} \geqslant 0, \quad \mathrm{i}=\mathrm{H}, \mathrm{T}, \quad t=1,2 .
\end{aligned}
$$

Denoting by $\mu$ the multiplier of the resource constraint and by $\gamma_{t}^{\mathrm{i}}$ the multipliers of the non-negativity constraints, labelling by a star their optimal values, the first order conditions ${ }^{8}$ are:

$$
\begin{aligned}
& u_{t}^{\prime}\left(q_{t}^{\mathrm{T} *}+q_{t}^{\mathrm{H} *}\right)-c_{t}^{\prime}\left(q_{t}^{\mathrm{T} *}\right)+\gamma_{t}^{\mathrm{T} *}=0 \\
& \text { and } u_{t}^{\prime}\left(q_{t}^{\mathrm{T} *}+q_{t}^{\mathrm{H} *}\right)-\mu^{*}+\gamma_{t}^{\mathrm{H} *}=0
\end{aligned}
$$

together with the complementary slackness conditions.

We will discuss in some detail the various possible types of solutions in Subsection 3.2. Before this, in order to get some intuition of the problem, we examine graphically the case where both processes are used in both periods. This case is illustrated in Fig. 1.

The central box of Fig. 1 provides a geometric illustration of the allocation of the water resource amongst the two periods. The breadth is equal to $S$, the global amount of the scarce natural resource that can be used over the two periods.

Let us assume that the sole available process is the hydroplant and that water is

\footnotetext{
${ }^{8}$ They are sufficient since the objective function is concave and the feasible set convex.
} 


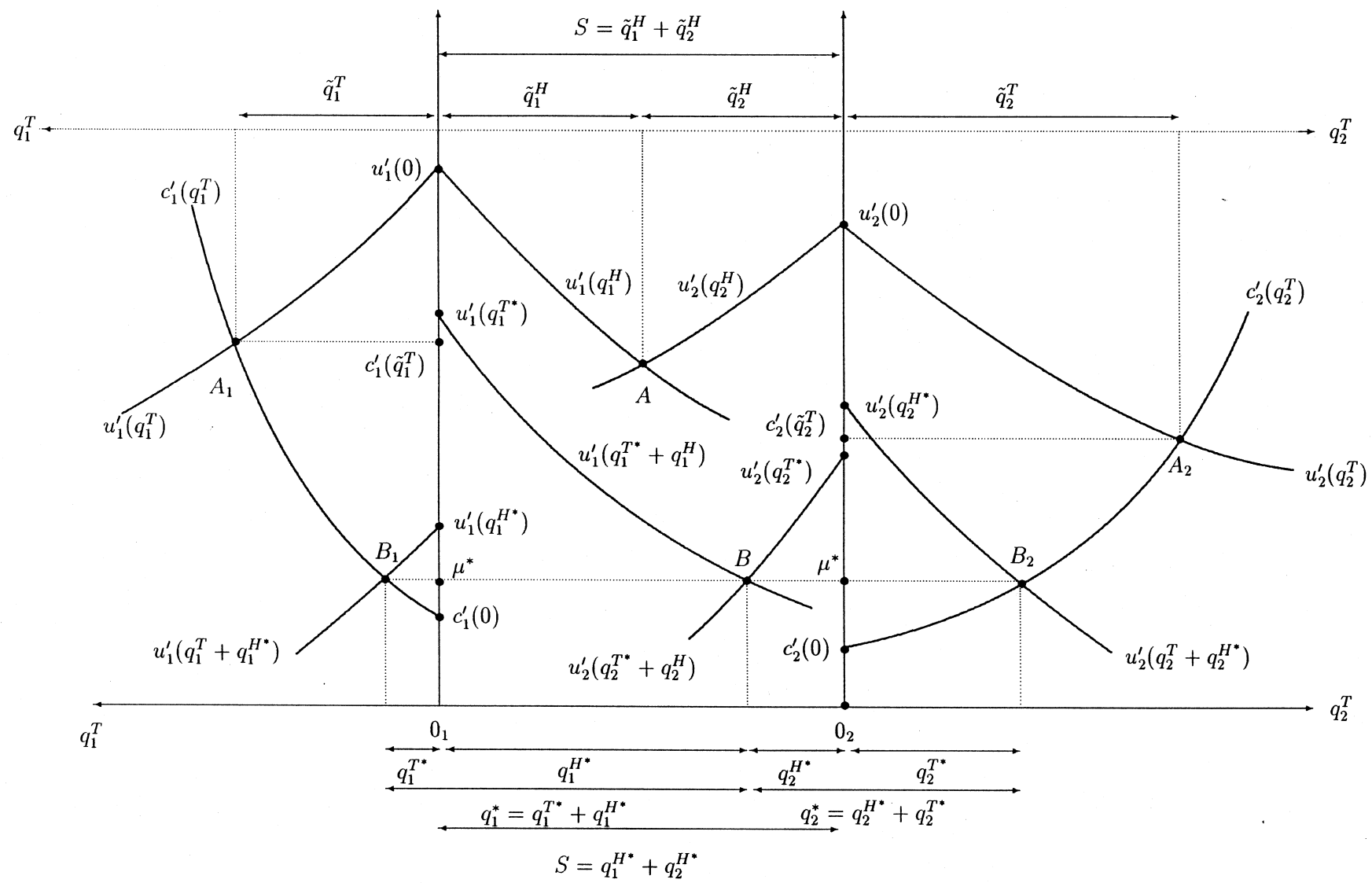

Fig. 1. The optimal assignment of plants. 
sufficiently scarce to be exhausted at the end of period 2. Then the marginal utility of the resource use is $u_{1}^{\prime}\left(q_{1}^{\mathrm{H}}\right)$ for the first period and $u_{2}^{\prime}\left(q_{2}^{\mathrm{H}}\right)$ for the second one. The decreasing function $u_{1}^{\prime}\left(q_{1}^{\mathrm{H}}\right)$ is plotted taking $0_{1}$ as origin and from the left to the right for increasing values of $q_{1}^{\mathrm{H}}$, whereas $u_{2}^{\prime}\left(q_{2}^{\mathrm{H}}\right)$ is drawn by taking $0_{2}$ as origin, and from the right to the left for increasing values of $q_{2}^{\mathrm{H}}$. Since the marginal cost of using the hydroplant is equal to zero, the optimal allocation of the whole $S$ between $q_{1}^{\mathrm{H}}$ and $q_{2}^{\mathrm{H}}$ makes the marginal values of consumption equal, resulting in point $A$ and consumptions $\tilde{q}_{1}^{\mathrm{H}}$ and $\tilde{q}_{2}^{\mathrm{H}}$ in Fig. 1 .

The use of the thermal plant in period 1 is illustrated in the left quadrant of the figure, $q_{1}^{\mathrm{T}}$ being plotted from the right to the left starting from $0_{1}$. Were the thermal plant the sole available generation process in period 1 , the marginal utility of the thermal energy would be given by $u_{1}^{\prime}\left(q_{1}^{\mathrm{T}}\right){ }^{9}$. Equating the marginal utility of $q_{1}^{\mathrm{T}}$ to its marginal cost $c_{1}^{\prime}\left(q_{1}^{\mathrm{T}}\right)$ results in $A_{1}$, implying an optimal consumption $\tilde{q}_{1}^{\mathrm{T}}$. The right part of Fig. 1 is illustrating the use of the thermal plant in period 2. Were the thermal plant the sole production process available in the second period the optimal use of the plant would occur at $A_{2}$ for a production level $\tilde{q}_{2}^{\mathrm{T}}$. The combination of the two production processes in both periods results in point $B$ for the hydraulic output and points $B_{1}$ and $B_{2}$ for the thermal outputs. At each period $t=1,2$, the marginal utility of using the thermal process given the use $q_{t}^{\mathrm{H} *}$ of hydraulic energy, $u_{t}^{\prime}\left(q_{t}^{\mathrm{H} *}+q_{t}^{\mathrm{T}}\right)$, must be equal to its marginal cost $c_{t}^{\prime}\left(q_{t}^{\mathrm{T}}\right)$, hence:

$$
u_{1}^{\prime}\left(q_{1}^{\mathrm{H} *}+q_{1}^{\mathrm{T} *}\right)=c_{1}^{\prime}\left(q_{1}^{\mathrm{T} *}\right) \quad \text { and } \quad u_{2}^{\prime}\left(q_{2}^{\mathrm{H} *}+q_{2}^{\mathrm{T} *}\right)=c_{2}^{\prime}\left(q_{2}^{\mathrm{T} *}\right) .
$$

Simultaneously the allocation of the water resource $S$ must be such that its marginal utility in period $1, u_{1}^{\prime}\left(q_{1}^{\mathrm{H}}+q_{1}^{\mathrm{T}} *\right)$, given the use of the thermal energy $q_{1}^{\mathrm{T} *}$, is equal to its marginal utility in period $2, u_{2}^{\prime}\left(q_{2}^{\mathrm{H}}+q_{2}^{\mathrm{T} *}\right)$, given the use of the thermal energy $q_{2}^{\mathrm{T}} *$, resulting in:

$$
u_{1}^{\prime}\left(q_{1}^{\mathrm{H} *}+q_{1}^{\mathrm{T} *}\right)=u_{2}^{\prime}\left(q_{2}^{\mathrm{H} *}+q_{2}^{\mathrm{T} *}\right)=\mu^{*} .
$$

Putting together (5) and (6) gives:

$$
u_{1}^{\prime}\left(q_{1}^{\mathrm{H} *}+q_{1}^{\mathrm{T} *}\right)=u_{2}^{\prime}\left(q_{2}^{\mathrm{H} *}+q_{2}^{\mathrm{T} *}\right)=\mu^{*}=c_{1}^{\prime}\left(q_{1}^{\mathrm{T} *}\right)=c_{2}^{\prime}\left(q_{2}^{\mathrm{T} *}\right),
$$

which is the fundamental characterization of the optimal use of the two types of processes when both are active in every period. The water resource which may be stored has a smoothing effect on the use of the thermal plant. Without hydraulic resources, the marginal costs and utilities of consumption in periods 1 and 2 may be different. By adequately allocating the water resource, this discrepancy is eliminated. More precisely, introducing water into the picture has two effects. The first one is that a new, but finite, resource is now available at low (zero) marginal

\footnotetext{
${ }^{9}$ Note that $u_{1}^{\prime}\left(q_{1}^{\mathrm{T}}\right)$ and $u_{1}^{\prime}\left(q_{1}^{\mathrm{H}}\right)$ are symmetrical vis-à-vis the vertical axis through $0_{1}$.
} 
cost. Clearly this low marginal cost resource has to be used first, thus reducing the marginal utility of the thermal energy in every period: $u_{t}^{\prime}\left(q_{t}^{\mathrm{H}}+q_{t}^{\mathrm{T}}\right)<u_{t}^{\prime}\left(q_{t}^{\mathrm{T}}\right)$, whatever $q_{t}^{\mathrm{H}}>0$, for all $q_{t}^{\mathrm{T}} \geqslant 0$. Thus, even if the water resource were not optimally allocated amongst the two periods, the thermal production of at least one of the periods (this period $t$ for which $q_{t}^{\mathrm{H}}>0$ ) would have to be decreased and the marginal cost of consumption would decrease as well. Simultaneously by optimally allocating the water resource, the discrepancy between the marginal cost of the thermal supplies is eliminated. This is the exact meaning of the arbitrage equation (7). Arbitrage is feasible at zero cost because water is storable at zero operating costs. The common value of the thermal marginal costs in both periods is the marginal value of water. A marginal increase in water supply $\mathrm{d} S$ could be used either in period 1 permitting a saving of $c_{1}^{\prime}\left(q_{1}^{\mathrm{T} *}\right) \mathrm{d} S=u_{1}^{\prime}\left(q_{1}^{\mathrm{T} *}+q_{1}^{\mathrm{H} *}\right) \mathrm{d} S$ or in period 2 permitting a saving of $c_{2}^{\prime}\left(q_{2}^{\mathrm{T} *}\right) \mathrm{d} S=u_{2}^{\prime}\left(q_{2}^{\mathrm{T} *}+q_{2}^{\mathrm{H} *}\right) \mathrm{d} S$. By (6) these two opportunity costs must be the same to result in an optimal allocation of water and they give the marginal value of the water resource, $\mu^{*}$.

In the case illustrated in Fig. 1, the marginal thermal cost in period 1 decreases from $c_{1}^{\prime}\left(\tilde{q}_{1}^{\mathrm{T}}\right)$ to $c_{1}^{\prime}\left(q_{1}^{\mathrm{T} *}\right)$ and the marginal thermal cost in period 2 decreases from $c_{2}^{\prime}\left(\tilde{q}_{2}^{\mathrm{T}}\right)$ to $c_{2}^{\prime}\left(q_{2}^{\mathrm{T} *}\right)=c_{1}^{\prime}\left(q_{1}^{\mathrm{T} *}\right)=\mu^{*}$. Both thermal quantities decrease, from $\tilde{q}_{1}^{\mathrm{T}}$ to $q_{1}^{\mathrm{T} *}$ in period 1 and from $\tilde{q}_{2}^{\mathrm{T}}$ to $q_{2}^{\mathrm{T} *}$ in period 2 . But since $u_{1}^{\prime}\left(q_{1}^{\mathrm{T} *}+q_{1}^{\mathrm{H} *}\right)<$ $u_{1}^{\prime}\left(\tilde{q}_{1}^{\mathrm{T}}\right)$ and $u_{2}^{\prime}\left(q_{2}^{\mathrm{T} *}+q_{2}^{\mathrm{H} *}\right)<u_{2}^{\prime}\left(\tilde{q}_{2}^{\mathrm{T}}\right)$, consumption increases in every period. ${ }^{10}$

\subsection{Corner solutions}

So far, the solution we have analyzed assigns a positive output to each station at each period. A priori, this is only one among sixteen possibilities since each output can be zero or strictly positive. Actually not all these solutions are feasible. For instance, $q_{t}^{\mathrm{T}}>0$ and $q_{1}^{\mathrm{H}}=q_{2}^{\mathrm{H}}=0$ cannot be a solution since the hydrogeneration is costless while the thermal generation is costly. ${ }^{11}$ Consequently, there remains a set of 12 solutions. But there is an obvious symmetry between the case $\left(q_{1}^{\mathrm{H}}>0\right.$, $\left.q_{2}^{\mathrm{H}}=0\right)$ and the case $\left(q_{1}^{\mathrm{H}}=0, q_{2}^{\mathrm{H}}>0\right)$ so that only eight cases deserve further inspection, half with positive hydrogeneration at both periods, half with zero hydrogeneration at one period.

Consider first the latter case and assume that $q_{1}^{\mathrm{H} *}=0$. Since $u_{1}^{\prime}(0)>c_{1}^{\prime}(0)$ we deduce that $q_{1}^{\mathrm{T} *}>0$ is defined by $u_{1}^{\prime}\left(q_{1}^{\mathrm{T} *}\right)=c_{1}^{\prime}\left(q_{1}^{\mathrm{T} *}\right)$ which is strictly positive.

\footnotetext{
${ }^{10}$ The implementation conditions of the first best as well as an example using a quadratic specification for cost and utility are given in Crampes and Moreaux (1999).

${ }^{11}$ Formally, suppose that $q_{t}^{\mathrm{H}}=0$ at both periods when $S>0$. Consequently $\mu=0$ and $u_{t}^{\prime}\left(q_{t}^{\mathrm{T}}\right) \leqslant 0$ by the second condition in (4). Then $q_{t}^{\mathrm{T}} \geqslant \hat{q}_{t}>0$ which means $c_{t}^{\prime}\left(q_{t}^{\mathrm{T}}\right)>0$ and the first condition in (4) cannot be satisfied.
} 
Consequently, $\mu^{*}>0$ so that $q_{2}^{\mathrm{H} *}=S$ by the complementary slackness condition. This means that when the utility from consumption is much higher and/or thermal generation is more costly in period 2 than in period 1 , then the whole water resource should be used in the peak period and during the off-peak period power should be exclusively generated by the thermal station. During period 2 , the peak period, additional power can be produced from the thermal unit $\left(q_{2}^{\mathrm{T} *}>0\right)$ or, on the contrary, the thermal station can generate nothing. The special case where the solution is $q_{1}^{\mathrm{H} *}=0, q_{2}^{\mathrm{H} *}=S, q_{1}^{\mathrm{T} *}>0, q_{2}^{\mathrm{T} *}=0$ is characterized by:

$$
u_{1}^{\prime}\left(q_{1}^{\mathrm{T} *}\right)=c_{1}^{\prime}\left(q_{1}^{\mathrm{T} *}\right)<u_{2}^{\prime}(S)=\mu^{*}<c_{2}^{\prime}(0)
$$

The last inequality in (8) means that the thermal marginal cost of any kilowatt at period 2 is higher than the (dual) marginal cost of water $\mu^{*}$, which results in $q_{2}^{\mathrm{T} *}=0$. The first inequality says that the needs in period 2 are so high that it is efficient to devote the whole stock of water to period 2 and to produce at period 1 with the thermal station $\left(q_{1}^{\mathrm{H} *}=0, q_{2}^{\mathrm{H} *}=S\right)$.

This type of corner solution may be counterintuitive for those who view water as a zero cost resource. But its value arises from its scarcity as compared to the needs at both periods. In the case we consider here, one may say that with respect to the low utility and thermal cost characteristics of period 1, water is scarce: the cheapest technology is the thermal plant. On the contrary, the thermal technology is very expensive at period 2 so that the allocation of the whole stock of water to this period is the best solution. Keeping the case of peak valuation in period 2, if the thermal cost were the same at both periods an additional output of electricity from the thermal equipment should be generated to complement the hydroelectricity generation. Consequently, the scarcity of the resource explains why it must be devoted to the peak period: water can have a very low (even zero) technical cost but a very high economic value.

Let us now consider the second set of corner solutions where $q_{t}^{\mathrm{H} *}>0$ at both periods. This is because, given the utility functions and the thermal cost functions, the water resource is plentiful and can be allocated among both periods. Then the energy from the power station is only a residual source of consumption. If $S$ is very large, the thermal station is useless in both periods. ${ }^{12}$ A sufficient condition for this to occur is $S>\hat{q}_{1}+\hat{q}_{2}$. In this case the social dual value of water is zero since the stock is not exhausted with optimal planning: $u_{t}^{\prime}\left(q_{t}^{\mathrm{T} *}=\hat{q}_{t}\right)=\mu^{*}=0$. Under less extreme conditions, the thermal unit is idle only at one period because of a high set-up cost $c_{t}^{\prime}(0)$ and a low utility of energy at that period.

\footnotetext{
${ }^{12}$ Actually, if $u_{1}^{\prime}\left(q_{1}^{\mathrm{H} *}\right)=u_{2}^{\prime}\left(q_{2}^{\mathrm{H} *}\right)=\mu^{*}<\min \left(c_{1}^{\prime}(0), c_{2}^{\prime}(0)\right)$ and, if $q_{1}^{\mathrm{H} *}+q_{2}^{\mathrm{H} *}=S$, then $q_{1}^{\mathrm{T} *}=$ $q_{2}^{\mathrm{T} *}=0$.
} 


\section{The monopoly}

We consider in this section the most output restricting institutional setting, a private monopoly maximizing its profits. Before examining the problem of the combined use of both types of generation processes, we first determine what would be the monopoly policy, were the hydraulic generation the sole available production process. Second, we analyze the private monopolist decisions when both technologies are available. Last we examine the case of a public monopoly constrained by the obligation to pay all costs, including the fixed costs of infrastructure, à la Boiteux-Ramsey.

\subsection{The management of the water resource by a private monopoly}

The problem of an hydro-monopolist is to determine the values of the $q_{t}$ variables, $t=1,2$, that solve:

$$
\begin{aligned}
& \text { (P.2) } \max _{\left\{q_{t}\right\}} \sum_{t=1,2} u_{t}^{\prime}\left(q_{t}\right) q_{t} \\
& \text { s.t. } S-q_{1}-q_{2} \geqslant 0 \text { and } q_{t} \geqslant 0, \quad t=1,2 .
\end{aligned}
$$

Labelling by superscript $\mathrm{m}$ the optimal values of the multipliers $\mu$ and $\gamma_{t}, t=1,2$, as well as the optimal values of the decision variables $q_{t}$, the first order conditions of the hydro-monopolist problem are:

$$
u_{t}^{\prime \prime}\left(q_{t}^{\mathrm{Hm}}\right) q_{t}^{\mathrm{Hm}}+u_{t}^{\prime}\left(q_{t}^{\mathrm{Hm}}\right)-\mu^{\mathrm{m}}+\gamma_{t}^{\mathrm{Hm}}=0, \quad t=1,2
$$

together with the usual complementary slackness conditions.

Assuming first that $q_{t}^{\mathrm{Hm}}, t=1,2$, are both strictly positive, and denoting by $R m_{t}\left(q_{t}\right)=u_{t}^{\prime \prime}\left(q_{t}\right) q_{t}+u_{t}^{\prime}\left(q_{t}\right)$ the marginal revenue function in period $t$, the above conditions imply that:

$$
R m_{1}\left(q_{1}^{\mathrm{Hm}}\right)=\mu^{\mathrm{m}}=R m_{2}\left(q_{2}^{\mathrm{Hm}}\right) .
$$

Since under a zero marginal cost assumption the marginal receipt is nothing but the marginal profit, the marginal receipt in period 1 must be equal to the marginal receipt in period 2 , their common value being the marginal value of the stock, $\mu^{\mathrm{m}}$. Note that these equalities have to be satisfied whether the stock constraint is binding or not, the marginal value $\mu^{\mathrm{m}}$ being equal to zero in the latter case. The case of a binding resource constraint is illustrated in Fig. 2.

Equating the marginal revenues results in point $M$ and the allocation of water $\left(q_{1}^{\mathrm{Hm}}, q_{2}^{\mathrm{Hm}}\right)$. Except when utility functions $u_{t}(\cdot)$ are identical in periods 1 and 2 , equating marginal revenues leads to different values of prices $p_{1}^{\mathrm{m}}=u_{1}^{\prime}\left(q_{1}^{\mathrm{Hm}}\right)$ and $p_{2}^{\mathrm{m}}=u_{2}^{\prime}\left(q_{2}^{\mathrm{Hm}}\right)$. It is interesting to compare the allocation $\left(q_{1}^{\mathrm{Hm}}, q_{2}^{\mathrm{Hm}}\right)$ with the optimal allocation $\left(q_{1}^{\mathrm{H} *}, q_{2}^{\mathrm{H} *}\right)$, point $A$ in Fig. 2 , obtained by equating the marginal 


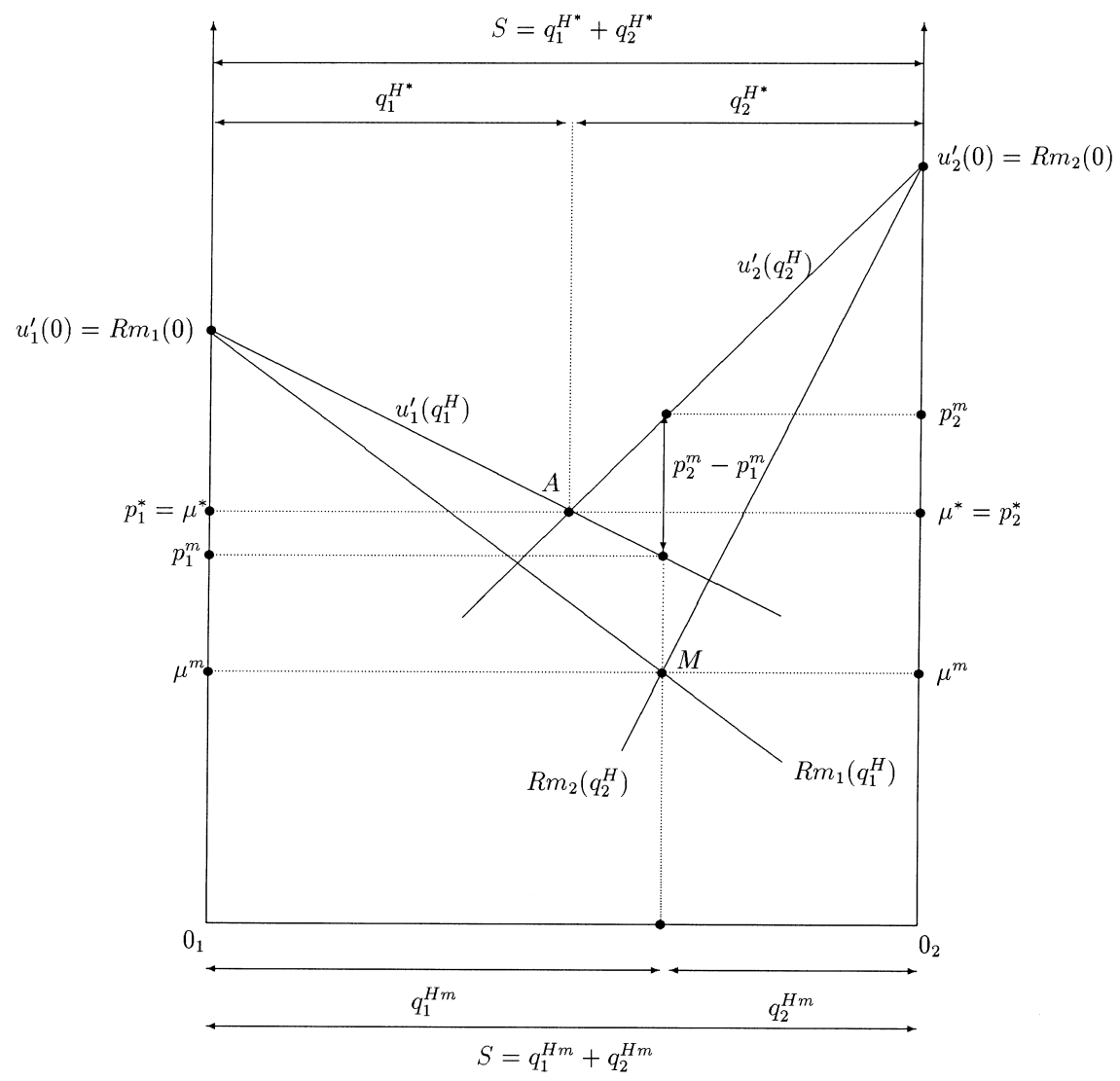

Fig. 2. Allocation of a scarce resource by a monopolist.

utilities in both periods. Under the present assumption of sufficiently high demand functions, the monopoly uses the whole resource stock $S$ so that the sole effects of a switch from optimal management to monopoly management are:

- first, a change in the allocation of $S$ between the two periods;

- second, the disappearance of the unicity of prices, ${ }^{13}$ and since the total quantity sold is the same, $S$, there must exist some period $t$ during which the monopoly price $p_{t}^{\mathrm{m}}$ is higher than the optimal price $p_{t}^{*}\left(p_{2}^{\mathrm{m}}>u_{2}^{\prime}\left(q_{2}^{\mathrm{H} *}\right)=p_{2}^{*}=\mu^{*}\right.$ in Fig. 2), while it is lower than the optimal price during the other period $\left(p_{1}^{\mathrm{m}}<u_{1}^{\prime}\left(q_{1}^{\mathrm{H} *}\right)=p_{1}^{*}=\mu^{*}\right.$ in Fig. 2);

\footnotetext{
${ }^{13}$ Except in the very special case where demand functions are identical in both periods.
} 
- third, the marginal value of the resource stock $S$ for the private monopoly $\left(\mu^{\mathrm{m}}\right)$ is lower than its marginal social value; this is a direct outcome of the monopoly behaviour driven by marginal revenues rather than by marginal utilities, since marginal revenues are lower than marginal utilities for all the quantities in every period.

When the whole stock $S$ is not used by the monopoly, the private value $\mu^{\mathrm{m}}$ is equal to zero. Note that now both prices $p_{1}^{\mathrm{m}}$ and $p_{2}^{\mathrm{m}}$ are higher than the unique optimal price $p_{1}^{*}=p_{2}^{*}=\mu^{*} \geqslant 0$.

Finally note that the problem of corner solutions is, to some extent, independent of the tightness of the resource constraint. If the demand in period $t$ is very high and the demand in period $t^{\prime}$ very low, so that $R m_{t}(S)>u_{t^{\prime}}^{\prime}(0)$, then the whole stock $S$ has to be used in period $t$ and the resource constraint is binding. But clearly if the water resource is in excess, the quantities sold by the monopolist in every period have to be both strictly positive, even if the demand function of some period is very low, but positive.

\subsection{Managing the two technologies}

Taking into account the thermal process leads to the following problem:

$$
\begin{aligned}
& \text { (P.3) } \max _{\left\{q_{t}^{\mathrm{i} i}\right\}} \sum_{t=1,2}\left\{u_{t}^{\prime}\left(q_{t}^{\mathrm{T}}+q_{t}^{\mathrm{H}}\right)\left[q_{t}^{\mathrm{T}}+q_{t}^{\mathrm{H}}\right]-c_{t}\left(q_{t}^{\mathrm{T}}\right)\right\} \\
& \text { s.t. } \quad S-q_{1}^{\mathrm{H}}-q_{2}^{\mathrm{H}} \geqslant 0 \text { and } q_{t}^{\mathrm{i}} \geqslant 0, \quad \mathrm{i}=\mathrm{H}, \mathrm{T}, \quad t=1,2
\end{aligned}
$$

The first order conditions are:

$$
\begin{aligned}
& R m_{t}\left(q_{t}^{\mathrm{Tm}}+q_{t}^{\mathrm{Hm}}\right)-c_{t}^{\prime}\left(q_{t}^{\mathrm{Tm}}\right)+\gamma_{t}^{\mathrm{Tm}}=0, \quad t=1,2 \\
& R m_{t}\left(q_{t}^{\mathrm{Tm}}+q_{t}^{\mathrm{Hm}}\right)-\mu^{\mathrm{m}}+\gamma_{t}^{\mathrm{Hm}}=0, \quad t=1,2
\end{aligned}
$$

and the complementary slackness conditions.

Let us consider the case $q_{t}^{\mathrm{im}}>0, \mathrm{i}=\mathrm{H}, \mathrm{T}, t=1,2$. From the above conditions we obtain:

$$
R m_{1}\left(q_{1}^{\mathrm{Tm}}+q_{1}^{\mathrm{Hm}}\right)=R m_{2}\left(q_{2}^{\mathrm{Tm}}+q_{2}^{\mathrm{Hm}}\right)=\mu^{\mathrm{m}}=c_{1}^{\prime}\left(q_{1}^{\mathrm{Tm}}\right)=c_{2}^{\prime}\left(q_{2}^{\mathrm{Tm}}\right) .
$$

Both marginal revenues and marginal thermal costs in every period must be equal to the private marginal value $\mu^{\mathrm{m}}$ of the resource stock $S$. Were the thermal process the sole available process, the marginal revenues and thermal costs in periods 1 and 2 could be different. The only maximizing profit condition would be:

$$
\operatorname{Rm}_{t}\left(q_{t}^{\mathrm{Tm}}\right)=c_{t}^{\prime}\left(q_{t}^{\mathrm{Tm}}\right), \quad t=1,2 .
$$


As in the welfare maximising case the effect of the water resource, storable at a zero marginal cost, is to reduce the discrepancy between marginal values in periods 1 and 2, here marginal revenues rather than marginal utilities or prices as in the case of optimal management.

Since the thermal marginal cost is positive, equating marginal revenue rather than price to the marginal cost results in an output restriction even if the whole resource stock is used by the monopolist. Beside this first effect, the second effect is to reallocate the use of the water stock among the two periods. Note also that as in the pure water case, the prices in periods 1 and 2 take generically different values.

\subsection{The regulated monopoly}

Now, we consider the case of a monopoly that controls the use of both techniques but with the special statute of "public firm" obliged to balance its budget, taking account of the fixed costs.

The problem is:

$$
\begin{array}{ll}
\text { (P4) } & \sum_{\left\{q_{t}^{\mathrm{i}}\right\}}\left\{u_{t}\left(q_{t}^{\mathrm{H}}+q_{t}^{\mathrm{T}}\right)-c_{t}\left(q_{t}^{\mathrm{T}}\right)\right\} \\
\text { s.t. } & \sum_{t=1,2}\left\{u_{t}^{\prime}\left(q_{t}^{\mathrm{H}}+q_{t}^{\mathrm{T}}\right)\left[q_{t}^{\mathrm{H}}+q_{t}^{\mathrm{T}}\right]-c_{t}\left(q_{t}^{\mathrm{T}}\right)\right\}-F^{\mathrm{H}}-F^{\mathrm{T}} \geqslant 0 \\
S- & q_{1}^{\mathrm{H}}-q_{2}^{\mathrm{H}} \geqslant 0 \text { and } q_{t}^{\mathrm{i}} \geqslant 0, \quad \mathrm{i}=\mathrm{H}, \mathrm{T}, \quad t=1,2
\end{array}
$$

where (18) is the break-even constraint taking into account the hydraulic fixed costs $F^{\mathrm{H}}$ and the thermal fixed costs $F^{\mathrm{T}}$.

Denoting by $\lambda$ the multiplier of the constraint (18), the first order conditions of (P4) are:

$$
\begin{array}{ll}
\operatorname{wrt} q_{t}^{\mathrm{H}}: & u_{t}^{\prime}\left(q_{t}^{\mathrm{H}}+q_{t}^{\mathrm{T}}\right)-\mu+\lambda R m_{t}\left(q_{t}^{\mathrm{T}}+q_{t}^{\mathrm{H}}\right)+\gamma_{t}^{\mathrm{H}}=0, \quad t=1,2 \\
\operatorname{wrt} q_{t}^{\mathrm{T}}: & u_{t}^{\prime}\left(q_{t}^{\mathrm{H}}+q_{t}^{\mathrm{T}}\right)-c_{t}^{\prime}\left(q_{t}^{\mathrm{T}}\right)+\lambda\left[R m_{t}\left(q_{t}^{\mathrm{T}}+q_{t}^{\mathrm{H}}\right)-c_{t}^{\prime}\left(q_{t}^{\mathrm{T}}\right)\right]+\gamma_{t}^{\mathrm{T}}=0, \\
& t=1,2
\end{array}
$$

together with the complementary slackness conditions.

Let us examine the case where all the second best production levels are positive. Denoting by $\epsilon_{t}>0$ the demand elasticity in period $t$ at point $q_{t}^{\mathrm{H}}+q_{t}^{\mathrm{T}}$, from the FOC's with respect to $q_{t}^{\mathrm{T}}$ we obtain:

$$
\frac{u_{t}^{\prime}\left(q_{t}^{\mathrm{H}}+q_{t}^{\mathrm{T}}\right)-c_{t}^{\prime}\left(q_{t}^{\mathrm{T}}\right)}{u_{t}^{\prime}\left(q_{t}^{\mathrm{H}}+q_{t}^{\mathrm{T}}\right)}=\frac{\lambda}{1+\lambda} \frac{1}{\epsilon_{t}}, \quad t=1,2 .
$$

Thus the relative mark-up over the thermal marginal cost, in each period $t$, must 
be proportional to the inverse of the demand elasticity in the corresponding period, the usual Boiteux-Ramsey rule. ${ }^{14}$ The FOC's wrt $q_{t}^{\mathrm{H}}$ lead to:

$$
\frac{u_{t}^{\prime}\left(q_{t}^{\mathrm{H}}+q_{t}^{\mathrm{T}}\right)-\mu /(1+\lambda)}{u_{t}^{\prime}\left(q_{t}^{\mathrm{H}}+q_{t}^{\mathrm{T}}\right)}=\frac{\lambda}{1+\lambda} \frac{1}{\epsilon_{t}}, \quad t=1,2 .
$$

The above conditions (20) and (21) imply that:

$$
c_{1}^{\prime}\left(q_{1}^{\mathrm{T}}\right)=\frac{\mu}{1+\lambda}=c_{2}^{\prime}\left(q_{2}^{\mathrm{T}}\right),
$$

that is the thermal marginal costs must be the same in both periods. Again this is the result of the smoothing effect of the zero cost storability of water.

The marginal value of the water stock is now $\mu=(1+\lambda) c_{t}^{\prime}\left(q_{t}^{\mathrm{T}}\right), t=1,2$. The effects of a marginal increase $\mathrm{d} S>0$ of the water stock, are twofold. The direct effect, $c_{t}^{\prime}\left(q_{t}^{\mathrm{T}}\right) \mathrm{d} S$, is to save operating costs. But there is a second effect due to the very fact that, having a zero operating cost, this increase of the water stock may be seen as relaxing the break-even constraint by $c_{t}^{\prime}\left(q_{t}^{\mathrm{T}}\right) \mathrm{d} S$. Since $\lambda$ is the multiplier associated to this constraint, the users' welfare can be increased by $\lambda c_{t}^{\prime}\left(q_{t}^{\mathrm{T}}\right) \mathrm{d} S$. This second effect is specific to the Boiteux-Ramsey context.

\section{Cournot competition: the open-loop game}

Let us now suppose that the industry has a duopolistic structure, each duopolist controlling one process. We examine in the present section an open-loop setting. Note that the inverse demand function in period $t, p_{t}\left(q_{t}^{\mathrm{T}}+q_{t}^{\mathrm{H}}\right)=u_{t}^{\prime}\left(q_{t}^{\mathrm{T}}+q_{t}^{\mathrm{H}}\right)$, is decreasing since $u_{t}^{\prime \prime}<0$. Moreover, we assume that the revenue functions, $R_{t}^{\mathrm{H}}\left(q_{t}^{\mathrm{H}}, q_{t}^{\mathrm{T}}\right)=p\left(q_{t}^{\mathrm{H}}+q_{t}^{\mathrm{T}}\right) q_{t}^{\mathrm{H}} \quad$ and $R_{t}^{\mathrm{T}}\left(q_{t}^{\mathrm{T}}, q_{t}^{\mathrm{H}}\right)=p\left(q_{t}^{\mathrm{H}}+q_{t}^{\mathrm{T}}\right) q_{t}^{\mathrm{T}}$, of the hydroproducer and thermal producer, respectively, are strictly concave, the first in $q_{t}^{\mathrm{H}}$ and the second in $q_{t}^{\mathrm{T}}$.

\subsection{Open-loop strategies and equilibrium}

In the open-loop setting, the strategy of operator $x, x \in\{\mathrm{H}, \mathrm{T}\}$ is a pair of quantities $q^{x}=\left\{q_{1}^{x}, q_{2}^{x}\right\}$, one for each period. A pair of strategies $\left(q^{\mathrm{H} c}, q^{\mathrm{T} c}\right)$ is an equilibrium if each one is the best response to the other.

The thermal operator solves the following problem, where $q_{t}^{\mathrm{H}}, t=1,2$, is taken as given:

$$
\text { (P.5.T) } \max _{\left\{q_{t}^{\mathrm{T}}\right\}} \sum_{t=1,2} p_{t}\left(q_{t}^{\mathrm{T}}+q_{t}^{\mathrm{H}}\right) q_{t}^{\mathrm{T}}-c_{t}\left(q_{t}^{\mathrm{T}}\right), \text { s.t. } q_{t}^{\mathrm{T}} \geqslant 0, \quad t=1,2
$$

The first order conditions are:

\footnotetext{
${ }^{14}$ Except if the fixed costs are sufficiently low and/or the marginal cost sufficiently increasing for the break-even constraint not to be binding. In this case, $\lambda=0$ and (20) gives the first best allocation.
} 


$$
p_{t}\left(q_{t}^{\mathrm{T}}+q_{t}^{\mathrm{H}}\right)+p_{t}^{\prime}\left(q_{t}^{\mathrm{T}}+q_{t}^{\mathrm{H}}\right) q_{t}^{\mathrm{T}}-c_{t}^{\prime}\left(q_{t}^{\mathrm{T}}\right)+\gamma_{t}^{\mathrm{T}}=0, \quad t=1,2
$$

associated with the complementary slackness conditions.

These first order conditions define the thermal operator's best response functions, denoted by $Q_{t}^{\mathrm{T}}\left(q_{t}^{\mathrm{H}}\right), t=1,2$. Since the revenue functions are strictly concave and the cost function strictly convex, this best response is uniquely defined and strictly decreasing with $q_{t}^{\mathrm{H}}$.

Consider now the hydro-manager's problem, where $q_{t}^{\mathrm{T}}, t=1,2$, is given:

$$
\text { (P.5.H) } \max _{\left\{q_{t}^{\mathrm{H}}\right\}} \sum_{t=1,2} p_{t}\left(q_{t}^{\mathrm{T}}+q_{t}^{\mathrm{H}}\right) q_{t}^{\mathrm{H}}
$$

$$
\text { s.t. } \quad S-q_{1}^{\mathrm{H}}-q_{2}^{\mathrm{H}} \geqslant 0 \text { and } q_{t}^{\mathrm{H}} \geqslant 0, \quad t=1,2
$$

The first order conditions are:

$$
p_{t}\left(q_{t}^{\mathrm{T}}+q_{t}^{\mathrm{H}}\right)+p_{t}^{\prime}\left(q_{t}^{\mathrm{T}}+q_{t}^{\mathrm{H}}\right) q_{t}^{\mathrm{H}}-\mu+\gamma_{t}^{\mathrm{H}}=0, \quad t=1,2
$$

If the resource constraint is binding with positive hydro-output in both periods, the operator of the hydro-station equates the marginal revenues in both periods, where the common value is the marginal value $\mu$ of the stock $S$. The allocation of the water stock among periods is determined on the basis of the thermal outputs in both periods. This means that the best response functions are:

$$
q_{t}^{\mathrm{H}}=Q_{t}^{\mathrm{H}}\left(q_{t}^{\mathrm{T}}, q_{t^{\prime}}^{\mathrm{T}}\right), \quad t, t^{\prime}=1,2, \quad t \neq t^{\prime}
$$

If the hydro-outputs are strictly positive, since $Q_{t}^{\mathrm{H}}(\cdot)$ is the solution of $R_{t}^{\mathrm{H}^{\prime}}\left(q_{t}^{\mathrm{H}}, q_{t}^{\mathrm{T}}\right)=R_{t^{\prime}}^{\mathrm{H}^{\prime}}\left(S-q_{t}^{\mathrm{H}}, q_{t^{\prime}}^{\mathrm{T}}\right)$, from the concavity of the revenue function it is easy to check that:

$$
\frac{\partial Q_{t}^{\mathrm{H}}}{\partial q_{t}^{\mathrm{T}}}=-\frac{R_{t}^{\mathrm{H}^{\prime \prime}}}{R_{t}^{\mathrm{H}^{\prime \prime}}+R_{t^{\prime}}^{\mathrm{H}^{\prime \prime}}}<0 \quad \text { and } \quad \frac{\partial Q_{t}^{\mathrm{H}}}{\partial q_{t^{\prime}}^{\mathrm{T}}}=\frac{R_{t}^{\mathrm{H}^{\prime \prime}}}{R_{t}^{\mathrm{H}^{\prime \prime}}+R_{t^{\prime}}^{\mathrm{H}^{\prime \prime}}}>0
$$

As for any standard competition model "à la Cournot" with substitutes, the best response function $Q_{t}^{\mathrm{H}}$ is a decreasing function of the output of its competitor in the same period $t$. But although demand in period $t$ does not depend upon prices in period $t^{\prime}, Q_{t}^{\mathrm{H}}$ is also positively parametered by the output of the thermal producer in the other period $q_{t^{\prime}}^{\mathrm{T}}$.

The open-loop Cournot equilibrium is that pair of strategies $\left(q^{T c}, q^{H c}\right)$ satisfying:

$$
q_{t}^{\mathrm{T} c}=Q_{t}^{\mathrm{T}}\left(q_{t}^{\mathrm{H} c}\right), q_{t}^{\mathrm{H} c}=Q_{t}^{\mathrm{H}}\left(q_{t}^{\mathrm{T} c}, q_{t^{\prime}}^{\mathrm{T} c}\right), \quad t, t^{\prime}=1,2, t \neq t^{\prime} .
$$

As this solution is somewhat unusual, we devote the next subsection to a graphic analysis of the equilibrium according to the value of $S$. 


\subsection{Graphic illustration of the open-loop Cournot equilibrium}

A Cournot duopolist is nothing but a monopolist that extracts profits from its residual demand. We showed in section 4 above how the hydro-monopoly quantities are determined as a function of $S$ or equivalently as a function of $\mu$, the costate variable associated to the stock constraint. In Fig. 3, the 0dcba line illustrates the allocations of water among $q_{1}^{\mathrm{H}}$ and $q_{2}^{\mathrm{H}}$ for alternative values of either $S$ or $\mu$, for given exogenously determined values of the quantities sold by the thermal supplier, quantities defining the residual hydro-producer's demands. Point $a$ corresponds to $\mu=0$ and $\left(q_{1}^{\mathrm{H} a}, q_{2}^{\mathrm{H} a}\right)$ is the allocation of $S^{a}$, the maximum stock the hydro-duopolist would like to possess given $q_{1}^{\mathrm{T}}$ and $q_{2}^{\mathrm{T}}$. For any $S^{\prime}>S^{a}$, this part $\Delta S^{\prime}=S^{\prime}-S^{a}$ of the stock would not be used. $S^{b}$ corresponds to a lower stock than $S^{a}$, hence to a higher dual value $\mu^{b}>0$. Now, assume that $u_{1}^{\prime}\left(q_{1}^{\mathrm{T}}\right)>u_{2}^{\prime}\left(q_{2}^{\mathrm{T}}\right)$ and that the absolute value of $u_{1}^{\prime \prime}\left(q_{1}^{\mathrm{T}}+q\right)$ is significantly lower than the absolute value of $u_{2}^{\prime \prime}\left(q_{2}^{\mathrm{T}}+q\right)$. Then there must exist some critical low stock $S^{c}$, at and below which the hydro-duopolist is supplying the sole period 1 market because for

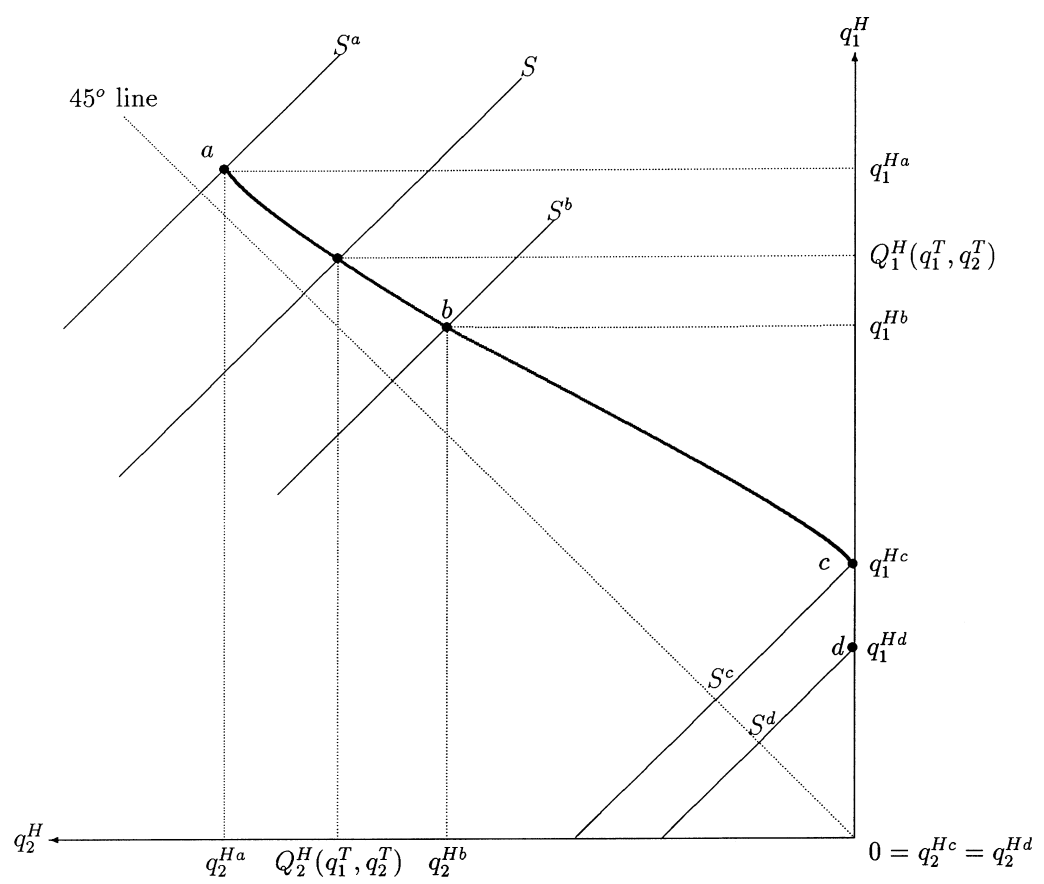

Fig. 3. The allocation of water by the hydro-duopolist. 
values such that $S \leqslant S^{c}, R_{1}^{\prime}\left(S+q_{1}^{\mathrm{T}}\right)>R_{2}^{\prime}\left(q_{2}^{\mathrm{T}}\right){ }^{15}$ Alternatively there exists some critical high value of $\mu$ for which and over which the hydro-producer will serve only period 1 . Thus, given $\left(q_{1}^{\mathrm{T}}, q_{2}^{\mathrm{T}}\right),\left(Q_{1}^{\mathrm{H}}\left(q_{1}^{\mathrm{T}}, q_{2}^{\mathrm{T}}\right), Q_{2}^{\mathrm{H}}\left(q_{1}^{\mathrm{T}}, q_{2}^{\mathrm{T}}\right)\right)$ is located at the intersection of the line $0 d c b a$ and the resource constraint line $q_{1}^{\mathrm{H}}+q_{2}^{\mathrm{H}}=S$. Clearly for alternative values of $\left(q_{1}^{\mathrm{T}}, q_{2}^{\mathrm{T}}\right)$ we have alternative $0 d c b a$ curves, hence different points $\left(Q_{1}^{\mathrm{H}}\left(q_{1}^{\mathrm{T}}, q_{2}^{\mathrm{T}}\right), Q_{2}^{\mathrm{H}}\left(q_{1}^{\mathrm{T}}, q_{2}^{\mathrm{T}}\right)\right)$ on the curve $S=q_{1}^{\mathrm{H}}+q_{2}^{\mathrm{H}}$, and also, alternative values of $\mu .^{16}$ In what follows, we shall call the curves like the $0 d c b a$ curve "quasi-best response curves" and they will be denoted by $B^{\mathrm{H}}\left(N ; q_{1}^{\mathrm{T}}, q_{2}^{\mathrm{T}}\right)=$ $\left(B_{1}^{\mathrm{H}}\left(N ; q_{1}^{\mathrm{T}}, q_{2}^{\mathrm{T}}\right), B_{2}^{\mathrm{H}}\left(N ; q_{1}^{\mathrm{T}}, q_{2}^{\mathrm{T}}\right)\right)$, where $\left(q_{1}^{\mathrm{T}}, q_{2}^{\mathrm{T}}\right)$ selects a curve and $N$ selects the point on this curve corresponding to an amount $N$ of natural resource. Under our regulatority assumptions:

$$
\frac{\partial B_{t}^{\mathrm{H}}}{\partial q_{t}^{\mathrm{T}}} \leqslant 0, \quad \frac{\partial B_{t}^{\mathrm{H}}}{\partial q_{t^{\prime}}^{\mathrm{T}}} \geqslant 0 \quad \text { and } \quad \frac{\partial B_{t}^{\mathrm{H}}}{\partial N} \geqslant 0, \quad t, t^{\prime}=1,2 \quad \text { and } \quad t^{\prime} \neq t,
$$

with strict inequalities if the water constraint is binding and $B_{t}^{\mathrm{H}}>0, t=1,2$.

Fig. 3 is inserted in Fig. 4 (northwest quadrant) in order to show the complete duopolist equilibrium. In the northeast quadrant we have drawn the best reply function $Q_{1}^{\mathrm{T}}\left(q_{1}^{\mathrm{H}}\right)$ of the thermal producer in period 1 and in the southwest quadrant its best reply function $Q_{2}^{\mathrm{T}}\left(q_{2}^{\mathrm{H}}\right)$ in period 2. For $\left(q_{1}^{\mathrm{T} c}, q_{2}^{\mathrm{T} c}\right)$ determining the quasi best response curve $B\left(N ; q_{1}^{\mathrm{T} c}, q_{2}^{\mathrm{T} c}\right)$, the allocation of water by the hydro-duopolist is given by $C^{\mathrm{H}}$ at the intersection of the $B\left(N ; q_{1}^{\mathrm{T} c}, q_{2}^{\mathrm{T} c}\right)$ curve and the resource constraint curve $S=q_{1}^{\mathrm{H}}+q_{2}^{\mathrm{H}}$ given $q_{t}^{\mathrm{H} c}, t=1,2$. The thermal duopolist's supplies are read on the corresponding reaction curves in the northeast quadrant for $t=1$ and the southwest quadrant for $t=2$. The $q_{1}^{\mathrm{T} c}$ and $q_{2}^{\mathrm{T} c}$ quantities must be those quantities parametering the $B\left(N ;\right.$.) curve from which $\left(q_{1}^{\mathrm{H} c}, q_{2}^{\mathrm{H} c}\right)$ has been obtained. This is the fixed point aspect of the drawing, illustrating the very fact that the open-loop equilibrium is a fixed point in $R_{+}^{4}$.

\subsection{Alternative types of equilibria}

At the equilibrium $\left(C^{\mathrm{H}}, C_{1}^{\mathrm{T}}, C_{2}^{\mathrm{T}}\right)$ shown in Fig. 4, the thermal plant is active in both periods 1 and 2 . But it must be clear that, with a large enough stock of water, and provided that $c_{t}^{\prime}(0)$ be positive at $t=1,2$, the thermal plant can be idle in one or both periods. Let $\dot{q}_{t}^{\mathrm{H}}$ be the hydro-supply over which the thermal duopolist is excluded from the period $t$ market: $q_{t}^{\mathrm{H}} \geqslant \dot{q}_{t}^{\mathrm{H}} \Rightarrow Q_{t}^{\mathrm{T}}\left(q_{t}^{\mathrm{H}}\right)=0, t=1,2$ (point $b$ in Fig. 4).

\footnotetext{
${ }^{15}$ Remember that the hydro-duopolist is a monopolist on the demand that is not served by the thermal plant. Then it is easy to check the assertion of the text using a box like in Fig. 2 .

${ }^{16}$ Provided that the thermal supply be not too high. If the thermal supply were very high, some water could be in excess. For such high thermal supply, the extremal point $a$ of the Odcba line is located under the resource constraint curve $S=q_{1}^{\mathrm{H}}+q_{2}^{\mathrm{H}}$.
} 


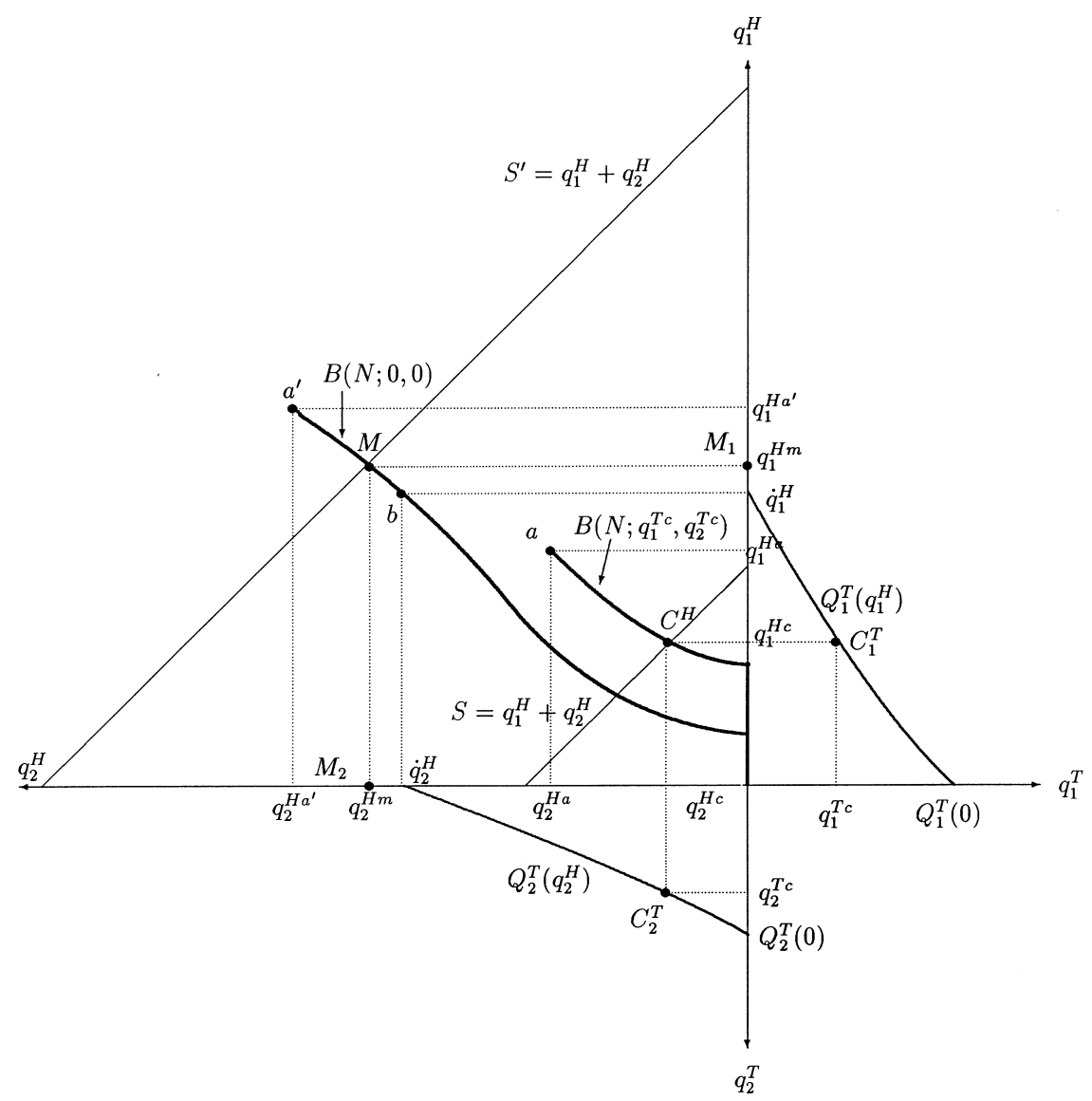

Fig. 4. The open-loop Cournot equilibrium.

In Fig. 4, we have drawn an equilibrium $\left(M, M_{1}, M_{2}\right)$ where the hydro-producer is a true monopolist selling quantities so large that the thermal-producer is excluded from the market in both periods. The $B(N ; 0,0)$ curve corresponds to what the hydro-supplier would produce, were the thermal duopolist producing nothing, in period 1 and in period 2. The non-zero terminal point, $a^{\prime}=\left(q_{1}^{\mathrm{Ha}}, q_{2}^{\mathrm{Ha}}\right)$, of the $B(N ; 0,0)$ curve must be such that $q_{t}^{\mathrm{H}{ }^{\prime}}>q_{t}^{\mathrm{H} a}, t=1,2$, where $a=\left(q_{1}^{\mathrm{H} a}, q_{2}^{\mathrm{H} a}\right)$ is the non-zero extremal point of the $B\left(N ; q_{1}^{\mathrm{T} c}, q_{2}^{\mathrm{T} c}\right)$ curve since $q_{t}^{\mathrm{T} c}>0, t=1,2$.

Note also that, since the marginal operating cost of the hydro-producer is equal to zero whereas the marginal operating costs of the thermal producer are positive and non-decreasing, we must have $q_{t}^{\mathrm{H} a^{\prime}}>\dot{q}_{t}^{\mathrm{H}}, t=1,2$. This implies that for a sufficiently high natural resource stock, the hydro-producer excludes the thermal producer from both markets. The sufficient condition for this exclusion is that the resource constraint line $S^{\prime}=q_{1}^{\mathrm{H}}+q_{2}^{\mathrm{H}}$ intersect the $B(N ; 0,0)$ curve over the sub- 
segment $\left[b, a^{\prime}\right]$. At the intersection point $M$ in Fig. 4, the quantities that the hydro-producer would sold, $q_{1}^{\mathrm{Hm}}$ and $q_{2}^{\mathrm{Hm}}$, are higher than, respectively, $\dot{q}_{1}^{\mathrm{H}}$ and $\dot{q}_{2}^{\mathrm{H}}$.

For the hydro-producer, the possibility of excluding its thermal competitor is strongly dependent upon the marginal start-up costs $c_{t}^{\prime}(0)$ which determine the critical values $\dot{q}_{t}^{\mathrm{H}}$, solutions of the equations:

$$
u_{t}^{\prime}\left(q_{t}^{\mathrm{H}}\right)=c_{t}^{\prime}(0), \quad t=1,2 .
$$

\section{Cournot competition: the closed-loop game}

The open-loop set-up is the right one either when the duopolists cannot observe the actions taken by their competitor during period 1, or when both duopolists can credibly commit at the outset of competition.

Since there is no uncertainty on the demand side, each duopolist may infer the action chosen by the other one from the observation of the price and its own action. Hence, except for the case where all the quantities had to be determined at the beginning for institutional reasons, more sophisticated strategies are to be considered.

The second period action of the hydro-operator is constrained by the stock of water at the end of period 1. Assuming that the initial stock is common knowledge and period 1 actions are observable, it is a matter of indifference to retain either the remaining stock of water or the first period action of the hydro-operator as the decisive variable determining period 2 actions by the competitors. Hence, in a markovian perspective, ${ }^{17}$ since the actions of the thermal operator during period 2 are not constrained by its actions during period 1 , the only pertinent variable for choosing the actions during period 2 is, for both the thermal operator and the hydro-operator, the action taken during period 1 by the hydro-competitor.

A Markov strategy of the thermal operator is a pair $\bar{q}^{\mathrm{T}}=\left(\bar{q}_{1}^{\mathrm{T}}, \bar{q}_{2}^{\mathrm{T}}\right)$ where $\bar{q}_{1}^{\mathrm{T}}$ is the quantity chosen for period 1 and $\bar{q}_{2}^{\mathrm{T}}$ is a function determining, for any $q_{1}^{\mathrm{H}} \in[0, S]$, the quantity $\bar{q}_{2}^{\mathrm{T}}\left(q_{1}^{\mathrm{H}}\right)$ he will put on the market during period 2 ; and a Markov strategy for the hydro-operator is a pair $\bar{q}^{\mathrm{H}}=\left(\bar{q}_{1}^{\mathrm{H}}, \bar{q}_{2}^{\mathrm{H}}\right)$ where $\bar{q}_{1}^{\mathrm{H}}(0 \leqslant$ $\bar{q}_{1}^{\mathrm{H}} \leqslant S$ ) is the quantity sold during period 1 whereas $\bar{q}_{2}^{\mathrm{H}}$ is a function giving, for any $q_{1}^{\mathrm{H}}$, the quantity $\bar{q}_{2}^{\mathrm{H}}\left(q_{1}^{\mathrm{H}}\right) \in\left[0, S-q_{1}^{\mathrm{H}}\right]$ he will sell during period 2 . The pair $\left(\bar{q}^{\mathrm{H}}, \bar{q}^{\mathrm{T}}\right)$ is a subgame perfect equilibrium if first it is an equilibrium and second, for any period 2 subgame starting from $q_{1}^{\mathrm{H}},\left(\bar{q}_{2}^{\mathrm{H}}\left(q_{1}^{\mathrm{H}}\right), \bar{q}_{2}^{\mathrm{T}}\left(q_{1}^{\mathrm{H}}\right)\right)$ is an equilibrium of the subgame.

Proceeding backward, let us first consider the period 2 subgame. The thermal operator maximizes the same objective function as in the second period of the open-loop case (see $(22))$, which gives the reaction function $Q_{2}^{\mathrm{T}}\left(q_{2}^{\mathrm{H}}\right)$.

\footnotetext{
${ }^{17}$ See Maskin and Tirole (1996).
} 
The hydroelectric producer solves the problem:

$$
\max _{q_{2}^{\mathrm{H}}} p_{2}\left(q_{2}^{\mathrm{H}}+q_{2}^{\mathrm{T}}\right) q_{2}^{\mathrm{H}} \quad \text { s.t. } \quad q_{2}^{\mathrm{H}} \leqslant S-q_{1}^{\mathrm{H}}
$$

resulting in a reaction function $\hat{Q}_{2}^{\mathrm{H}}\left(q_{2}^{\mathrm{T}}\right)$ parametered by $S-q_{1}^{\mathrm{H}}$. According to the value of $S-q_{1}^{\mathrm{H}}, \hat{Q}_{2}^{\mathrm{H}}\left(q_{2}^{\mathrm{T}}\right)$ may be constrained or not. If $S-q_{1}^{\mathrm{H}}>\hat{Q}_{2}^{\mathrm{H}}\left(q_{2}^{\mathrm{T}}\right)$, we have a usual asymmetric one-period Cournot game since the hydro station is working at zero operating costs.

Let us assume that $S-q_{1}^{\mathrm{H}}=\hat{Q}_{2}^{\mathrm{H}}\left(q_{2}^{\mathrm{T}}\right)$ in period 2. Then the period 2 equilibrium is:

$$
q_{2}^{\mathrm{H}}=S-q_{1}^{\mathrm{H}}, \quad q_{2}^{\mathrm{T}}=Q_{2}^{\mathrm{T}}\left(S-q_{1}^{\mathrm{H}}\right),
$$

so that the period 1 game appears as follows:

- for the hydroelectric producer:

$$
\max _{q_{1}^{\mathrm{H}}} \quad p_{1}\left(q_{1}^{\mathrm{H}}+q_{1}^{\mathrm{T}}\right) q_{1}^{\mathrm{H}}+p_{2}\left(S-q_{1}^{\mathrm{H}}+Q_{2}^{\mathrm{T}}\left(S-q_{1}^{\mathrm{H}}\right)\right)\left(S-q_{1}^{\mathrm{H}}\right)
$$

- and for the thermal producer:

$$
\begin{gathered}
\max _{q_{1}^{\mathrm{T}}} \quad p_{1}\left(q_{1}^{\mathrm{H}}+q_{1}^{\mathrm{T}}\right) q_{1}^{\mathrm{T}}-c_{1}\left(q_{1}^{\mathrm{T}}\right)+p_{2}\left(S-q_{1}^{\mathrm{H}}+Q_{2}^{\mathrm{T}}\left(S-q_{1}^{\mathrm{H}}\right)\right) Q_{2}^{\mathrm{T}}\left(S-q_{1}^{\mathrm{H}}\right) \\
-c_{2}\left(Q_{2}^{\mathrm{T}}\left(S-q_{1}^{\mathrm{H}}\right)\right) .
\end{gathered}
$$

The first order conditions of these problems are:

- for the hydroelectric duopolist, if $q_{1}^{\mathrm{H}}>0$,

$$
\begin{aligned}
& p_{1}^{\prime}\left(q_{1}^{\mathrm{H}}+q_{1}^{\mathrm{T}}\right) q_{1}^{\mathrm{H}}+p_{1}\left(q_{1}^{\mathrm{H}}+q_{1}^{\mathrm{T}}\right)-\left(1+\frac{\mathrm{d} Q_{2}^{\mathrm{T}}}{\mathrm{d} q_{2}^{\mathrm{H}}}\right) p_{2}^{\prime}\left(S-q_{1}^{\mathrm{H}}+Q_{2}^{\mathrm{T}}\left(S-q_{1}^{\mathrm{H}}\right)\right) \\
& \times\left(S-q_{1}^{\mathrm{H}}\right)-p_{2}\left(S-q_{1}^{\mathrm{H}}+Q_{2}^{\mathrm{T}}\left(S-q_{1}^{\mathrm{H}}\right)\right)=0 .
\end{aligned}
$$

- for the thermal duopolist, if $q_{1}^{\mathrm{T}}>0$,

$$
p_{1}^{\prime}\left(q_{1}^{\mathrm{H}}+q_{1}^{\mathrm{T}}\right) q_{1}^{\mathrm{T}}+p_{1}\left(q_{1}^{\mathrm{H}}+q_{1}^{\mathrm{T}}\right)-c_{1}^{\prime}\left(q_{1}^{\mathrm{T}}\right)=0
$$

The difference between the open loop and the closed-loop Markov equilibria is that in the closed-loop setting when equating its period 1 and period 2 marginal revenues, the hydroelectric producer takes into account, the reaction of the thermal producer in period $2, \mathrm{~d} Q_{2}^{\mathrm{T}} / \mathrm{d} q_{2}^{\mathrm{H}}$, whereas it does not in the open-loop setting. ${ }^{18}$ This additional effect puts more weight on period 2 because $\mathrm{d} Q_{2}^{\mathrm{T}} / \mathrm{d} q_{2}^{\mathrm{H}}<0$. Hence

\footnotetext{
${ }^{18}$ Suppose that $\gamma_{1}^{\mathrm{H}}=\gamma_{2}^{\mathrm{H}}=0$ in (25) and substitute $\mu$ for the marginal revenue of the other period. Then compare this first order condition with (28).
} 
considering a transfer of water from period $1\left(\mathrm{~d} q_{1}^{\mathrm{H}}<0\right)$ toward period 2 , the relevant marginal revenue is greater in the closed-loop setting since the increase of supply $\mathrm{d} q_{2}^{\mathrm{H}}>0$ will be partially compensated by the production decrease $\mathrm{d} Q_{2}^{\mathrm{T}} / \mathrm{d} q_{1}^{\mathrm{H}}$ $\mathrm{d} q_{2}^{\mathrm{H}}$ of the thermal producer. In the closed-loop equilibrium, this would result in a lower period 1 supply and a higher period 2 supply as compared with the open-loop equilibrium, as far as the resource constraint is effective and the hydro-producer is active at both periods.

\section{Concluding remarks}

In the electricity industry, the same output can be obtained from very heterogeneous equipment: gas or coal burning, nuclear reaction, wind or water turbine, etc. ${ }^{19}$ The thermal stations where fossil minerals are burnt to produce steam have an intrinsic static feature at the individual level: the fuel is a flow that can be bought on upstream markets so that an increase in generation today does not burden future power generations. This is not true for hydro stations using water resource accumulated in dams: it is renewable only on a yearly basis but non renewable within the year so that any use of water to produce a kilowatt today is lost for tomorrow's consumption. Consequently, when thermal plants are competing with technologies that are intrinsically nonstationary, they should be dynamically planned. Yet, so far the economic models of competition in power generation have static characteristics. To challenge this lack of dynamism, we have proposed a simple model where a thermal station faces an hydro station. With this technical setting, we have shown analytically and geometrically that despite its static characteristics, the optimized output from the thermal station is determined by the intertemporal specification of costs and utility. We have proved it in the case of a social planner who maximizes the net total utility from electricity consumption as well as in the case of a private monopolist and when two private firms compete in quantities.

Various extensions of this model can be considered but none seems likely to change the main points of the paper:

(i) First, the introduction of uncertainty (on the demand, or on the fuel price, or on the water inflows) would make the model more realistic. Nevertheless, uncertainty in the demand for electricity is more a long term problem (investment decision) than a short term one (production decision). Therefore, it would not affect drastically our short term modelling.

(ii) Other types of competition (in prices or in supply functions) and a larger number of markets (futures) should be tested. One can also consider more intricate market structures, for instance with at least two thermal generators and/or two hydro-producers. A structure with a fixed number of hydro incumbents and a lot of

\footnotetext{
${ }^{19}$ See Boyd (1996) and Johansson et al. (1993) for a catalogue of the techniques.
} 
thermal generators is more likely to be what will occur in the medium term, since entry is a very long term decision in the hydroelectric sector while it is very easy to enter with gas turbines.

(iii) To take into account the capacity constraint of the thermal station would have an effect on our model only if its residual demand were so high that the thermal station would produce at full capacity at each period: its short run generation planning would be obviously static. But in this case, the owner of the thermal plant has strong incentives to develop his capacity and the model should be extended to long run decisions.

(iv) Water has various alternative uses that appear as competitors when there exists a limited volume of resource. Consequently, the utility from water should be redefined to include agricultural, domestic and industrial usages other than electric generation. Our model sheds some light on what the opportunity cost of using water may be in these alternative activities. However, note that the problem of the opportunity cost is not a simple one. For instance, in most cases, water for agricultural uses is turbined before release, which means an additional time constraint for the hydrogenerator(s) rather than a mere decrease in the stock of water available for electricity generation. Hence, the dual value of water, as determined in this paper, is an upper bound of the true opportunity cost since the water is not totally lost after power generation.

(v) One interesting extension of the model is the introduction of pollution as a byproduct of the thermal generation. With this environmental cost, the less polluting hydro technology should be encouraged and the optimal dispatching should be biased in its favour in a way that depends on the pollution damages and on the discount rate. As for the other extensions, long term and short term effects must be carefully distinguished. For given capacities of both thermal and hydrogeneration, the corrective effects of pollution come from the smoothing of polluting damages within the year. At some latitudes, the environmental smoothing effect and the energy cost smoothing effect work in the same direction because more hydroelectric generation allows to reduce the smog during winter. But environmental and energy cost effects can conflict, for instance because the development of air conditioning can change the peak demand season from winter to summer. In this case most of the water resource will be used in summer while the polluting thermal plants will worsen the smog in winter.

(vi) We end this list with the problem of designing an institutional framework able to implement the first best or, at least, to limit the market power of generators. In the countries where a spot market for electricity has been installed, the hydro electric generators do not behave in the same way as their competitors: for instance they buy cheap electricity at night to restore their stock of water by pumping it upstream; sometimes, they propose electricity at zero cost when the resource is superabundant. For these reasons and those presented in (iv), it would be necessary to compare the efficiency of alternative institutional settings, for 
example with a public firm in charge of the allocation of water while the other types of resources can be managed on private grounds.

\section{Acknowledgements}

We are indebted for their comments to the participants at the seminar on Regulation at the Universidad Argentina De la Empresa, the Workshop on Electricity at IDEI and the World Congress of Environmental and Resource Economists (Venice, 1998). The referee and the editor suggested useful modifications to improve the first submitted version.

\section{References}

Borenstein S., Bushnell, J., 1997. An empirical analysis of the potential for market power in California's electricity industry. University of California Energy Institute, Working paper, September.

Boyd, G. (Ed.), 1996. Renewable Energy. Oxford U.P., Oxford.

Crampes, C., Moreaux, M., 1999, Water resource and power generation, ERNA-INRA, WP 99.05.025, Toulouse.

Green, R.J., Newbery, D.M., 1992. Competition in the British electricity spot market. Journal of Political Economy 100, 929-953.

Johansson, T.B., Kelly, H., Reddy, A.K.N., William, R.H. (Eds.), 1993. Renewable Energy. Earthean Publ., London and Island Press, Washington, DC.

Klemperer, P.D., Meyer, M., 1989. Supply function equilibria in oligopoly under uncertainty. Econometrica 57, 1243-1277.

Maskin, E., Tirole, J., 1996. Markov perfect equilibrium I; observable actions. Mimeo, GREMAQ, Université de Toulouse I.

Ocaña, C., Romero, A., 1998. A simulation of the Spanish electricity pool. Comisión Nacional del Sistema Eléctrico, Madrid W.P. DT 005/98 http://www.csen.es/hojas/fram3.htm

Scott, T.J., Read, E.G., 1996. Modelling hydro reservoir operation in a deregulated electricity market. International Transactions in Operational Research 3 (3), 243-254.

Von der Fehr, N.H.M., Harbord, D., 1993. Spot market competition in the UK electricity industry. Economic Journal 103, 531-546.

Williamson, O.E., 1966. Peak-load pricing and optimal capacity under indivisibility constraints. American Economic Review 56, 810-827.

Wolak, F.A., Patrick, R.H., 1997. The impact of rules and market structure on the price determination process in the England and Wales electricity market. Mimeo, Department of Economics, Stanford University.

Wolfram, C.D., 1998. Measuring duopoly power in the British electricity spot market. Mimeo, Department of Economics, Harvard University. 